\title{
AS MÚLTIPLAS FUNÇÕES DA AGRICULTURA FAMILIAR: UM ESTUDO SOBRE A CONSERVAÇÃO/PRESERVAÇÃO DOS RECURSOS NATURAIS E DA PAISAGEM RURAL DA LOCALIDADE DA GLÓRIA - CANGUÇU-RS
}

\author{
Queli Rejane da Silva KONZGEN ${ }^{1}$ \\ Giancarla SALAMONI ${ }^{2}$
}

\section{Resumo}

A valorização da multifuncionalidade da agricultura familiar ocorre desde os anos de 1990 no Brasil, mas as múltiplas funções atribuídas a este grupo de agricultores fazem parte da realidade histórica desses sujeitos, com reflexos na organização do espaço rural. O trabalho aborda a conservação/preservação dos recursos naturais e da paisagem rural que compreende uma das funções da noção de multifuncionalidade. 0 objetivo central deste artigo é caracterizar, a partir de parâmetros qualitativos, elementos que conformam a relação entre conservação/preservação dos recursos naturais e manutenção da paisagem na localidade da Glória, 10 distrito do município de Canguçu/ RS. Observa-se que o uso intensivo de agrotóxicos na produção agrícola, principalmente na produção de tabaco, afeta os agroecossistemas locais, alterando a paisagem rural. Por fim, pode-se afirmar que esta função encontra restrições nos espaços da agricultura familiar pesquisada.

Palavras-chave: Multifuncionalidade. Agricultura familiar. Espaço rural. Ambiente.

\section{Abstract \\ The multiple functions of family farming: a study on the conservation/ preservation of natural resources and the rural landscape in the locality of Glória - Canguçu-RS}

The valorization of the family farming multifunctionality occurs since the 1990 years in Brazil, but the multiple functions attributed to these farmer groups are part of the historical reality of these subjects, with repercussions in the rural space organization. The work approaches the conservation/preservation of natural resources and the rural landscape which comprises one of the functions of the notion of multifunctionality. The aim of this paper is to characterize, from qualitative parameters, elements that make up the relation between conservation/preservation of natural resources and maintenance of the landscape in the locality of Glória, first district of the municipality of Canguçu/RS. It is observed that the intensive use of agrochemicals in agricultural production, mainly in the tobacco, affects the local agroecosystems, changing the rural landscape. Finally, it can be affirmed that this function finds restrictions in the spaces of the family farming researched.

Key words: Multifunctionality. Family farming. Rural space. Environment.

\footnotetext{
1 Mestranda no Programa de Pós-Graduação em Geografia da Universidade Federal do Rio Grande. Bolsista CAPES. ICHI/FURG, Avenida Itália, Km 8, Rio Grande/RS - CEP: 96203-900. E-mail: kellykonzgen@yahoo.com.br

2 Professora Doutora na Universidade Federal de Pelotas (UFPel). ICH-UFPel, Rua Coronel Alberto Rosa, 154, Centro - Pelotas/RS. CEP. 96010-770. E-mail: gi.salamoni@yahoo.com.br
} 


\section{INTRODUÇÃO}

Desde os anos de 1990, tem sido possível perceber a valorização de novas funções associadas à agricultura familiar no Brasil. Por um lado, com a construção de políticas públicas, o que colaborou para o reconhecimento social e normativo da categoria, e, por outro lado, com o aumento dos problemas ambientais, o que contribuiu para uma valorização do mundo rural, modificando, assim, a perspectiva sobre o papel deste grupo social. Com isso, o país adota, na referida década, o conceito de multifuncionalidade como um instrumento de política pública para apoio e promoção da agricultura familiar. Porém, a noção de multifuncionalidade tem suas origens, sobretudo, na França. Segundo Carneiro e Maluf (2003), a multifuncionalidade:

[...] rompe com o enfoque setorial e amplia o campo das funções sociais atribuídas à agricultura, que deixa de ser entendida apenas como produtora de bens agrícolas. Ela se torna responsável pela conservação dos recursos naturais (água, solos, biodiversidade e outros), do patrimônio natural (paisagem) e pela qualidade dos alimentos (CARNEIRO; MALUF, 2003, p. 19).

O objetivo deste artigo é caracterizar a conservação/preservação ${ }^{3}$ dos recursos naturais e da paisagem rural da localidade da Glória, 10 distrito do município de Canguçu/RS, a partir de parâmetros previamente definidos, a fim de compreender uma das funções da multifuncionalidade da agricultura familiar identificada na realidade brasileira.

O município de Canguçu está localizado na região fisiográfica da Serra do Sudeste, no Escudo Cristalino Sul-rio-grandense, conforme a Figura 1. Canguçu é um município predominantemente rural e de economia fundamentada nas dinâmicas sociais e produtivas da agricultura familiar, cuja formação se dá a partir da colonização açoriana no século XVIII, e da alemã, pomerana e italiana no século XIX.

A diversidade de formas de organização espacial do rural em Canguçu está relacionada aos aspectos físico-naturais, ao processo de formação histórica e à significativa presença da agricultura familiar. O município possui um número expressivo de pequenas propriedades familiares, sendo chamado de "capital nacional da agricultura familiar". O número de estabelecimentos agropecuários do município de Canguçu compreende um total de 9.881 locais, dos quais 8.774 são estabelecimentos familiares e 1.107 são estabelecimentos não familiares ou patronais (IBGE, 2006).

\footnotetext{
3 Existem dois conceitos muito utilizados na área ambiental e diretamente relacionados com os pressupostos do desenvolvimento sustentável: preservação e conservação. Conservação implica em uso racional de um recurso natural, ou seja, em adotar um manejo de forma a obter rendimentos garantindo a sustentabilidade do ambiente. Já preservação apresenta um sentido mais restrito, significando a ação de apenas proteger um ecossistema ou recurso natural de dano ou degradação, ou seja, não utilizá-lo, mesmo que racionalmente e de modo planejado. Esses conceitos estão presentes no Novo Código Florestal Brasileiro (ARAGUAIA, 2011).
} 


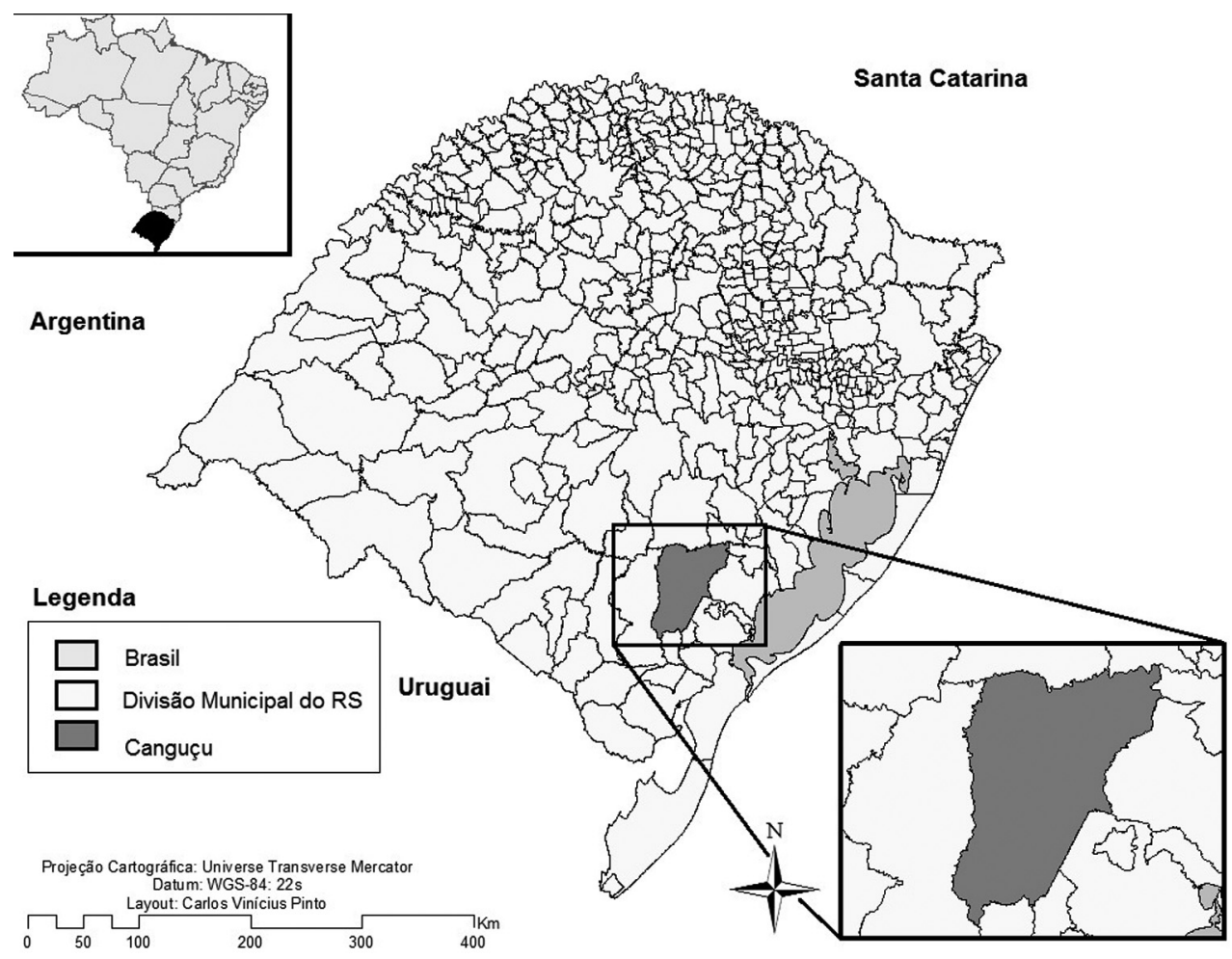

Figura 1 - Mapa de localização do município de Canguçu/RS

Fonte: Elaborado por Carlos Vinícius Pinto, 2015.

Os caminhos teórico-metodológicos para a construção deste estudo seguiram as seguintes etapas: 1 ) revisão bibliográfica sobre o tema da multifuncionalidade; 2) caracterização da área de estudo por meio de dados secundários; 3) elaboração de parâmetros para investigar cada uma das funções da multifuncionalidade; 4) realização de entrevistas, por meio de roteiro semiestruturado, durante a primeira quinzena do mês de agosto de 2016, com agricultores familiares da localidade da Glória, atendidos pela Empresa de Assistência Técnica e Extensão Rural (EMATER) - Canguçu e com vínculo na Chamada Pública da Sustentabilidade. De acordo com a EMATER Canguçu (2016), a referida Chamada tem como objetivo planejar as ações, executálas e avaliá-las (tanto atividades individuais quanto coletivas), com vistas ao desenvolvimento sustentável das unidades de produção familiar. Ainda segundo a EMATER Canguçu (2016), a localidade da Glória possui 24 agricultores assistidos na mencionada chamada pública, dos quais, por meio de uma seleção aleatória, foram entrevistados doze. A escolha da localidade justifica-se pelo fácil acesso ao campo e pela expressividade do fenômeno da multifuncionalidade da agricultura familiar. A opção pelo universo do projeto da Chamada Pública da Sustentabilidade vem ao encontro do tema central da pesquisa.

Este artigo faz parte de um Trabalho de Conclusão de Curso defendido em março de 2017 junto ao Curso de Licenciatura em Geografia da Universidade Federal 
de Pelotas. Cabe salientar que, durante o trabalho, o uso das aspas compreende a citação da bibliografia consultada, e do itálico, a transcrição das falas dos entrevistados.

\section{BREVE CONCEPÇÃO TEÓRICA SOBRE A MULTIFUNCIONALIDADE DA AGRICULTURA FAMILIAR NO BRASIL}

Carneiro e Maluf (2003) definiram quatro funções da multifuncionalidade da agricultura familiar na realidade brasileira. A reprodução socioeconômica das famílias rurais é a função que faz referência à geração de trabalho e renda que possibilita às famílias permanecerem no meio rural com condições dignas. A promoção da segurança alimentar das próprias famílias rurais e da sociedade abrange a produção para o autoconsumo e para a comercialização. A agricultura familiar promove a segurança alimentar, seja na disponibilidade e no acesso aos alimentos, seja em sua qualidade. A manutenção do tecido social e cultural refere-se à valorização das relações com a natureza, às relações com parentes e vizinhos (sociabilidade) e à reprodução das culturas locais. A agricultura é vista como um "modo de vida" que vai além da dimensão econômica da atividade agrícola. A conservação/preservação dos recursos naturais e da paisagem rural diz respeito ao uso de recursos e a sua manutenção sustentável. A discussão sobre esta função necessita ser expandida, identificando os impactos positivos e negativos provocados pela agricultura na paisagem rural.

O debate sobre a multifuncionalidade pretende, segundo Cardoso, Flexor e Maluf (2003, p. 60), "reinterpretar o papel dos estabelecimentos rurais numa sociedade mais atenta à preservação do meio ambiente, à especificidade da paisagem rural e à qualidade dos alimentos".

Identifica-se, na multifuncionalidade, a perspectiva de um novo paradigma para - desenvolvimento rural, ancorado na relação entre sustentabilidade e multifuncionalidade. Sachs (1993 apud GERARDI; SALAMONI, 2001) sugere um conceito de sustentabilidade para o desenvolvimento, para que este seja capaz de meIhorar as condições de vida das comunidades e, ao mesmo tempo, respeitar os limites da capacidade dos ecossistemas.

Há uma relação entre multifuncionalidade e sustentabilidade, a partir do reconhecimento de que o agricultor familiar associa a produção agrícola com a conservação dos recursos naturais, considerando o meio ambiente não apenas a base de produção, mas um espaço relacionado à vida do agricultor e à reprodução social da família.

Wanderley (2003, p. 14) afirma que a multifuncionalidade da agricultura familiar "poderá ajudar a fazer emergir a consciência sobre a ampla e diversificada contribuição dos agricultores para o dinamismo da sociedade, e reforçar uma perspectiva inovadora do desenvolvimento rural".

\section{PERFIL DAS FAMÍLIAS DE AGRICULTORES PESQUISADOS}

A localidade da Glória representa o recorte espacial da pesquisa e está localizada no $1^{0}$ distrito do município de Canguçu/RS. Sobre o sexo dos membros das famílias dos agricultores entrevistados, 21 são mulheres e 23 são homens. A mulher 
associa as atividades agrícolas e não agrícolas, participa geralmente de todo o processo de produção e reprodução da unidade agrícola familiar, do cuidado das crianças e do trabalho doméstico, exercendo uma jornada tripla de trabalho e desempenhando um papel importante na agricultura familiar. Contudo, em muitos casos, seu trabalho não é reconhecido, sendo visto apenas como "ajuda".

Na composição etária dos membros das famílias, seis têm entre 0 a 09 anos, oito entre 10 a 19 anos, vinte e cinco entre 20 a 59 anos e cinco entre 60 a 70 anos ou mais. Nota-se o predomínio dos adultos, ou seja, força de trabalho ativa. Segundo Bonini (2004), na família camponesa, as crianças e os mais velhos colaboram nas tarefas de menor esforço físico. Os homens exercem as atividades mais pesadas na lavoura e o gerenciamento da propriedade, e a mulher exerce múltiplas funções na unidade familiar, mas, em muitos casos, ocorre a desvalorização de seu trabalho.

Conforme a Tabela 1, a maioria dos membros das famílias, ou seja, 27 pessoas possuem o ensino fundamental incompleto. Destaca-se que três pessoas possuem ensino superior completo nos cursos de Administração, Licenciatura em Matemática e Economia Doméstica, todas do sexo feminino. Rua e Abramovay (2000) afirmam que muitos jovens do sexo masculino param de estudar para se dedicarem às atividades agrícolas, mas as mulheres continuam estudando porque as perspectivas de herdarem a terra são pequenas.

\section{Tabela 1 - Escolaridade dos membros das famílias}

\begin{tabular}{lc}
\hline \multicolumn{1}{c}{ Escolaridade } & Número de Pessoas \\
\hline Ensino Fundamental Incompleto & 27 \\
Ensino Fundamental Completo & 04 \\
Ensino Médio Incompleto & 06 \\
Ensino Médio Completo & 03 \\
Ensino Superior Incompleto & - \\
Ensino Superior Completo & 03 \\
Analfabeto & - \\
Não está em idade escolar & 01 \\
\hline Total & $\mathbf{4 4}$ \\
\hline
\end{tabular}

Fonte: Pesquisa de campo, 2016.

As atividades agrícolas são as que têm maior importância para que a família permaneça no meio rural, segundo os agricultores entrevistados, e isso se verifica na Tabela 2, mas a aposentadoria, o auxílio-doença e as atividades não agrícolas também são relevantes nos ingressos monetários da propriedade. 
Tabela 2 - Atividades que têm maior importância para a permanência da família no meio rural

\begin{tabular}{lc}
\hline \multicolumn{1}{c}{$\begin{array}{c}\text { Atividades com maior } \\
\text { importância }\end{array}$} & $\begin{array}{c}\text { Número de } \\
\text { agricultores }\end{array}$ \\
\hline Hortaliças, flores e serviço de pedreiro & 01 \\
Aposentadoria e hortaliças & 01 \\
Pêssego e aposentadoria & 01 \\
Auxílio-doença & 01 \\
Tabaco & 02 \\
Pêssego, tomate e tabaco & 01 \\
Pêssego & 02 \\
Tomate & 01 \\
Hortaliças, tomate & 01 \\
Atividades de professora e caminhoneiro & 01 \\
Produção de mudas & 01 \\
\hline Fonte: Pesquisa de
\end{tabular}

Fonte: Pesquisa de campo, 2016.

\section{A CONSERVAÇÃO/PRESERVAÇÃO DOS RECURSOS NATURAIS E DA PAISAGEM RURAL NA ESCALA LOCAL}

Com base na revisão teórica realizada ao longo da pesquisa, definiram-se os parâmetros especificados na Figura 2 para analisar cada uma das funções da multifuncionalidade da agricultura familiar na escala local. Lembrando que este artigo pretende caracterizar apenas uma função, ou seja, a conservação/ preservação dos recursos naturais e da paisagem rural.

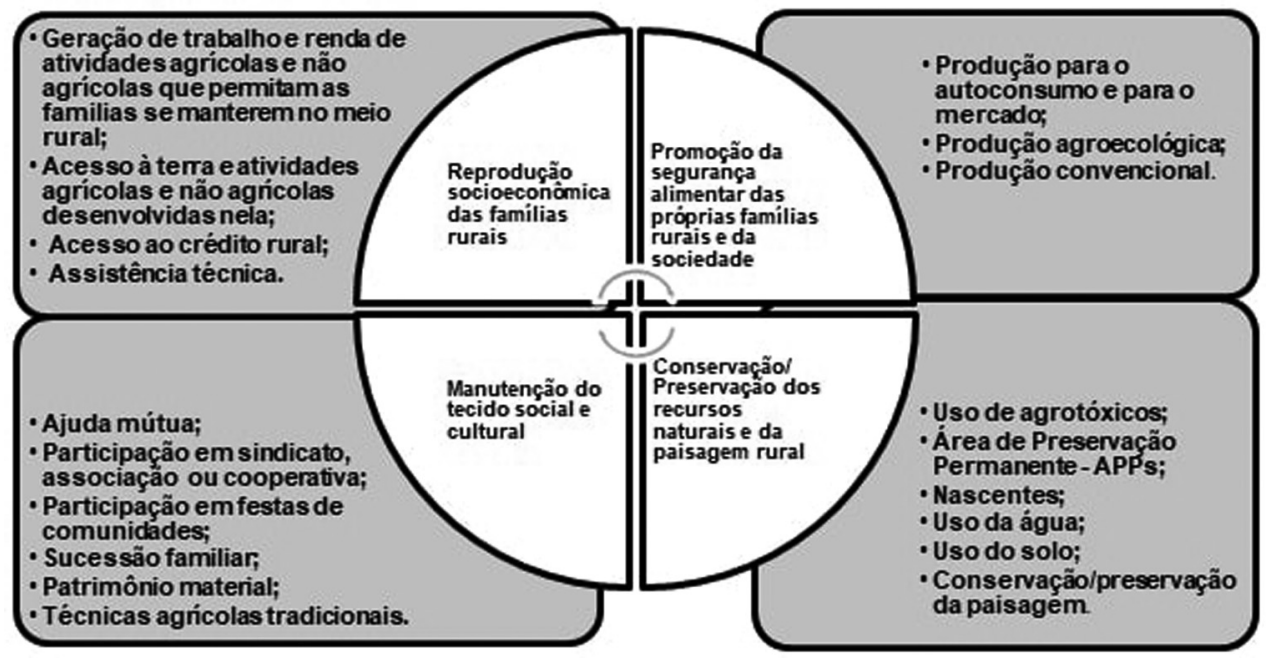

Figura 2 - Parâmetros da multifuncionalidade da agricultura familiar Fonte: Adaptado de Carneiro; Maluf (2003). 
Segundo Maluf (2003), a preservação dos recursos naturais e da paisagem rural deve considerar as relações entre a agricultura praticada pelas famílias rurais e o território no qual estão inseridas e identificar as contribuições (ou danos) da agricultura para a manutenção da paisagem rural.

Hespanhol (2008) afirma que ainda predominam explorações com o uso de técnicas nocivas ao ambiente, com a utilização inadequada de tecnologias em grandes, médias e pequenas propriedades, bem como com o caráter rudimentar dos sistemas de produção tradicional e práticas de explorações de diferentes magnitudes.

O solo é um fundamental componente do ambiente, recobrindo a porção superficial do terreno, tendo, dentre outras, a função de suporte da vida animal e vegetal. Sobre o uso do solo (Tabela 3) no âmbito pesquisado, a área cultivada compreende a área plantada com produtos vegetais (com culturas temporárias ou permanentes), com cultivo de espécies exóticas para reflorestamento, e tem como destino o consumo próprio (humano e alimentação dos animais) e o mercado. A área cultivada engloba a área em repouso, que consiste no descanso ou repouso das terras cultiváveis para, assim, tornar o solo mais fértil. A pastagem natural abrange a área de vegetação com espécies forrageiras naturais da região, usadas para a criação de animais. A mata nativa compreende um conjunto de plantas nativas de determinada região, com condições necessárias para seu desenvolvimento, tais como água, luz e calor, sendo difícil a identificação da interferência humana. A mata exótica abrange espécies de plantas originárias de outras regiões ou países. Essas plantas podem se adaptar tão bem que se proliferam e avançam sobre a vegetação nativa, podendo causar grandes desequilíbrios ecológicos. A Área de Preservação Permanente (APP) é destinada à proteção de solos, águas e matas ciliares, segundo Teixeira e Fruet (2014). Os autores ainda consideram como APP as florestas e demais formas de vegetação natural localizadas às margens de rios e lagos, as áreas de encontro de lagos e lagoas naturais, de reservatórios de águas artificiais, no encontro das nascentes e olhos de água perenes, nas encostas com declividade superior a $45^{\circ}$, no topo de morros e serras. As áreas não utilizáveis são o conjunto de afloramentos rochosos, caminhos de lavoura, áreas próximas das residências dos agricultores, entre outros.

\section{Tabela 3 - Uso do solo nas propriedades pesquisadas}

\begin{tabular}{lcc}
\hline \multicolumn{1}{c}{ Uso do Solo } & Número de Hectares & \% \\
\hline Área Cultivada & 78,1 & 55 \\
Mata & 26,98 & 19 \\
Pastagem Natural & 14,2 & 10 \\
APP & 12,78 & 09 \\
Área Não Utilizada & 9,94 & 07 \\
\hline Total & 142 & 100 \\
\hline
\end{tabular}

Fonte: Pesquisa de campo, 2016.

Onze dos entrevistados praticam uma ou mais técnicas de conservação do solo, como adubação verde, rotação de cultura, plantio direto e curva de nível. Observou-se a importância da conservação do solo na visão da maioria dos entrevistados, sendo salientado que a prática contribui para o aumento da produtividade, diminuição do uso de agrotóxicos, diminuição da ocorrência de pragas e ervas daninhas, entre outros.

Quando questionados sobre quais são os recursos hídricos disponíveis na propriedade, três responderam que possuem cacimba (cisterna), três têm sanga (córrego), 
cacimba e açude, dois dizem ter sanga e cacimba, dois possuem apenas sanga, um tem arroio e cacimba, e um dos entrevistados possui na propriedade cacimba e açude.

No total dos entrevistados, oito usam irrigação na agricultura para os cultivos de tomate, verduras e flores, assim como no viveiro de mudas. A água é obtida pelo uso de motor (elétrico ou gasolina/óleo combustível) e por queda natural, retirada de cacimbas, açudes, sangas e arroios.

Segundo Pereira et al. (2011, p. 140), "as nascentes são afloramentos do nível freático na superfície do terreno, e são pontos iniciais de cursos de água". Do total de doze propriedades estudadas, dez possuem nascentes de curso d'água. Dentre os cuidados tomados pelos agricultores na conservação das nascentes, estes afirmaram que mantêm vegetação próximo aos mananciais. Um agricultor elencou que, além de manter a vegetação, evita o uso de agrotóxicos nas proximidades, outro não planta perto das nascentes e um entrevistado está eliminando o eucalipto para plantar floresta nativa próximo das nascentes.

Segundo Calheiros et al. (2004), as nascentes de curso d'água são de suma importância no controle da erosão do solo por meio de estruturas físicas e barreiras vegetais. A vegetação protege o solo, evitando erosões, desmoronamento de encostas, contribuindo assim para a preservação das nascentes, as quais, no meio rural, são utilizadas para uso doméstico, higiene pessoal, criação de animais e irrigação.

Os entrevistados demonstraram uma grande preocupação na manutenção das nascentes, haja vista que todos relataram que usam práticas de conservação. No entanto, percebeu-se que, na prática, existe uma falta de orientação técnica quanto ao uso dos agrotóxicos, por exemplo. Igualmente, nota-se a presença de espécies artificiais, como o eucalipto, próximo das nascentes. Ambas as práticas podem culminar na contaminação e até no desaparecimento desses mananciais.

Acerca do uso de agrotóxicos nas propriedades estudadas, a maioria dos agricultores usam significativas quantidades do produto para a produção agrícola, conforme a Figura 3. Um exemplo disso foi o relatado por um dos entrevistados em relação ao uso dos insumos agrícolas: sempre tem que colocar um pouco, senão não vem, até na horta tem que colocar. Outro relatou que usa o herbicida tanto na produção para o mercado quanto na produção para o autoconsumo, principalmente na horta doméstica que se localiza próxima da residência. Segundo Veiga et al. (2006), a aplicação de agrotóxicos pode contaminar o solo e os sistemas hídricos, resultando numa degradação ambiental que tem como consequência prejuízos à saúde humana e animal e alterações significativas no ecossistema.

Nota-se a presença de embalagens de agrotóxicos descartadas incorretamente (queima, despejo nos cursos d'água, etc.) em algumas das propriedades pesquisadas. O descarte incorreto de embalagens vazias de agrotóxicos torna-se um perigo para o homem, animais e o ambiente. Elas são fontes de contaminação de nascentes, córregos e rios que abastecem tanto as propriedades rurais quanto as cidades (INPEV, 2006).

Sobre a manutenção da paisagem, cabe destacar que, entre os geógrafos, existe um consenso de que a paisagem, embora tenha sido estudada sob ênfases diferenciadas, resulta da relação dinâmica de elementos físicos, biológicos e antrópicos. Ela não é apenas um fato natural, mas engloba a existência humana (MAXIMIANO, 2004). 


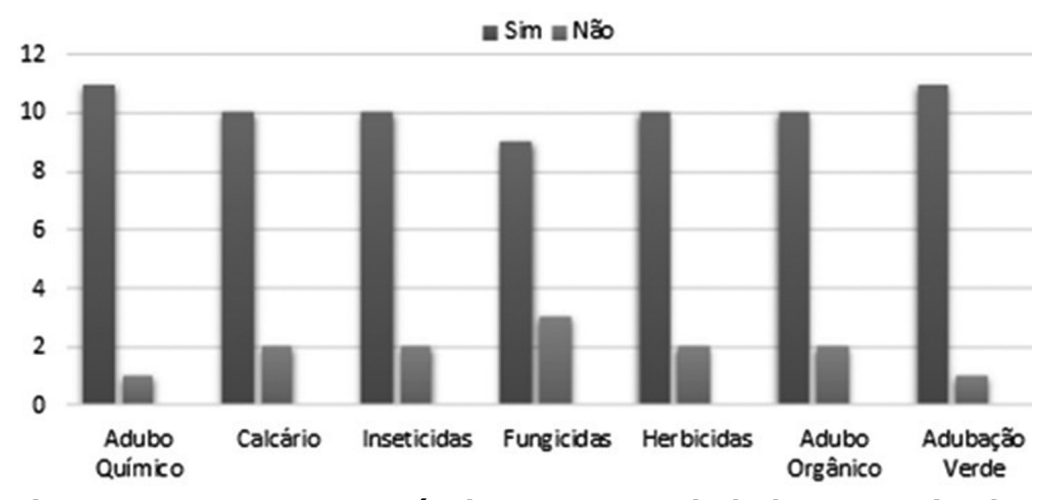

Figura 3 - Insumos agrícolas nas propriedades pesquisadas

Fonte: Pesquisa de campo, 2016.

Os entrevistados foram questionados sobre a paisagem preferida para o trabaIho e para o descanso e o porquê da escolha. A lavoura foi escolhida como paisagem preferida para o trabalho por ser o lugar de obtenção da renda familiar e dos produtos para o autoconsumo. Já a sombra ou a casa, que são paisagens naturais e artificiais, respectivamente, foram eleitas como lugares que são destinados para o descanso e convívio com a família. Santos (2004 apud COSTA, 2012) afirma que a paisagem resulta da acumulação de tempos, e Ribeiro (2007 apud COSTA, 2012) acredita que o que the confere uma dada identidade pode ser, em um primeiro plano, resultado de marcas no espaço ou de formas reconhecíveis e delimitáveis, as quais compõem uma unidade orgânica.

As paisagens, segundo Costa (2012), são construídas de forma conjugada pelo homem e pela natureza. Elas compreendem a relação da sociedade com seu espaço ao longo do tempo. Acrescentadas ao ambiente natural, as forças culturais, sociais e econômicas, de forma interna ou externa, influenciam as condições físicas com que se apresentam.

\section{CONSIDERAÇÕES FINAIS}

As múltiplas funções da agricultura familiar na localidade da Glória se manifestam de inúmeras formas. A conservação/preservação dos recursos naturais e da paisagem rural se apresenta de forma restrita. Apesar das preocupações sobre as questões ambientais nas propriedades rurais, na prática, a maioria dos agricultores usa significativas quantidades de agrotóxicos na produção, que contaminam os ecossistemas e os agroecossistemas e degradam a paisagem rural. Considerando que os agricultores pesquisados fazem parte do projeto da Chamada Pública da Sustentabilidade, os resultados esperados ainda se encontram limitados, porque, na realidade, apenas um agricultor está em período de transição agroecológica, os demais adotam a agricultura convencional e com poucas perspectivas para o desenvolvimento de uma produção sustentável.

A multifuncionalidade contribui para o desenvolvimento rural, que passa pela formulação de políticas públicas. Dessa forma, é necessário, na localidade da Glória, 
pensar em estratégias e políticas públicas para o planejamento e gestão dos recursos naturais e da paisagem rural, considerando as demandas e necessidades dos agricultores familiares, mediados por agentes de pesquisa e extensão rural.

\section{REFERÊNCIAS}

ARAguaiA, Mariana. Preservacionismo/Conservacionismo: A busca da sustentabilidade. Disponível em < http://mundoeducacao.bol.uol.com.br/biologia/ preservacao-ambiental.htm>. Acesso em: 05 set. 2017.

BONINI, Cristiane Vieira. A importância da mulher na agricultura familiar: 0 exemplo das trabalhadoras rurais na colônia Osório - Cerrito Alegre - Pelotas - RS. 82f. Trabalho de Conclusão de curso (Graduação em Geografia) - Universidade Federal de Pelotas, Pelotas, 2004.

CALHEIROS, Rinaldo de Oliveira et al. Preservação e recuperação de nascentes. Comitê de Bacias Hidrográficas. Piracicaba, 2004.

CARDOSO, Joel Henrique; FLEXOR, Georges; MALUF, Renato. Multifuncionalidade da agricultura em áreas de assentamentos rurais: o caso de Abelardo Luz (SC). In: CARneiro, Maria José; MALUF, Renato S. (Org.). Para além da produção: Multifuncionalidade e Agricultura Familiar. Rio de Janeiro: MAUAD, 2003. p. 60-73.

CARNeIRO, Maria José; MALUF, Renato Sérgio (Org.). Para além da produção: multifuncionalidade e agricultura familiar. Rio de Janeiro: MAUAD, 2003.

COSTA, Rita De Cassia Almeida da. A importância da observação da paisagem rural para a preservação dos valores culturais locais e como garantia da sobrevivência saudável do homem na contemporaneidade. In: COLÓQUIO IBERO-AMERICANO, 2., Anais... Belo Horizonte, 2012. p. 1-19.

EMPRESA DE ASSISTÊNCIA TÉCNICA E EXTENSÃO RURAL (EMATER). Município de Canguçu, Rio Grande do Sul, 2016.

GERARDI, Lucia Helena de Oliveira; SALAMONI, Giancarla. Princípios sobre o ecodesenvolvimento e suas relações com a agricultura familiar. In: GERARDI, Lucia Helena Oliveira; MENDES, Iandara Alves. (Orgs). Teoria, Técnicas, Espaços e Atividades: temas de Geografia Contemporânea. Rio Claro: Programa de PósGraduação em Geografia - UNESP; Associação de Geografia Teorética - AGETEO, 2001. p. 73-96.

HESPANHOL, Antonio Nivaldo. Desafios da geração de renda em pequenas propriedades e a questão do desenvolvimento rural sustentável no Brasil. In: ALVES, Adilson Francelino; CORRIJO, Beatriz Rodrigues; CANDIOTTO, Luciano Zanetti Pessôa. (Org.). Desenvolvimento territorial e agroecologia. São Paulo: Expressão Popular, 2008. p. 81-94.

INSTITUTO BRASILEIRO DE GEOGRAFIA E ESTATÍSTICA (IBGE). Censo Agropecuário 2006. Disponível em: <http://www.ibge.gov.br>. Acesso em: 25 jun. 2016.

INSTITUTO NACIONAL DE PROCESSAMENTO DE EMBALAGENS DE AGROTÓXICOS VAZIAS (INPEV). Relatório anual 2006, 2006. p. 3-121.

MALUF, Renato Sérgio. A multifuncionalidade da agricultura na realidade rural brasileira. In: CARNEIRO, Maria José; MALUF, Renato Sérgio (Org.). Para além da produção: multifuncionalidade e agricultura familiar. Rio de Janeiro: MAUAD, 2003. p. 135-152. 
MAXIMIANO, Liz Abad. Considerações sobre o conceito de paisagem. Ra'ega, Curitiba, n. 8, p. 83-91, 2004.

PEREIRA, Pedro Henrique Vaz et al. Nascentes: Análise e discussão dos conceitos existentes. Fórum Ambiental da Alta Paulista. São Paulo, v. 7, n. 2, p. 139-151, 2011.

RUA, Maria das Graças; ABRAMOVAY, Miriam. Companheiras de Luta ou "Coordenadoras de Panelas"? Brasília: Ed. Unesco, 2000.

TEIXEIRA, César; FRUET, Ana Paula Burin. Deveres do proprietário de imóvel rural em matéria de preservação ambiental e a utilização de instrumentos econômicos na proteção florestal. In: DÖRR, Andréa Cristina et al. Práticas \& Saberes em meio ambiente. Curitiba: Appris, 2014. p. 11-37.

VEIGA, Marcelo Mota et al. Análise da contaminação dos sistemas hídricos por agrotóxicos numa pequena comunidade rural do Sudeste do Brasil. Caderno de Saúde Pública, Rio de Janeiro, v. 22, n. 11, p. 2391-2399, nov. 2006.

WANDERLEY, Maria de Nazareth Baudel. Prefácio. In: CARNEIRO, Maria José; MALUF, Renato Sérgio (Org.). Para além da produção: multifuncionalidade e agricultura familiar. Rio de Janeiro: Mauad, 2003. p. 9-16. 